\title{
Differential expression of estradiol and estrogen receptor $\alpha$ in severe preeclamptic pregnancies compared with normal pregnancies
}

\author{
GUOWU YIN ${ }^{1 *}$, XIAOMING ZHU ${ }^{1 *}$, CHUN GUO $^{2 *}$, YANG YANG $^{3 *}$, TAO HAN ${ }^{4 *}$, LEI CHEN $^{1}$, \\ WEN YIN $^{5}$, PING GAO ${ }^{1}$, HUIZHONG ZHANG $^{6}$, JIE GENG ${ }^{7}$, JULEI WANG ${ }^{8}$ and LIANG LIANG ${ }^{9}$ \\ ${ }^{1}$ Department of Obstetrics and Gynecology, Tangdu Hospital, Fourth Military Medical University, Xi'an, Shanxi 710038; \\ ${ }^{2}$ Department of Obstetrics and Gynecology, Armed Police Corps Hospital, Hohhot, Inner Mongolia 010040; \\ ${ }^{3}$ Department of Obstetrics and Gynecology, Affiliated Hospital of Xi'an Medical University, Xi'an, Shanxi 710077; \\ ${ }^{4}$ Department of Orthopedics, Tangdu Hospital, Fourth Military Medical University, Xi'an, Shanxi 710038; \\ ${ }^{5}$ Department of Microbiology, School of Preclinical Medicine, Fourth Military Medical University, Xi'an, Shanxi 710032; \\ Departments of ${ }^{6}$ Medical Laboratory, ${ }^{7}$ Teaching and Medical Administration and ${ }^{8}$ Neurosurgery, Tangdu Hospital, \\ Fourth Military Medical University, Xi'an, Shanxi 710038; ${ }^{9}$ Department of Medical Genetics and \\ Developmental Biology, Fourth Military Medical University, Xi'an, Shanxi 710032, P.R. China
}

Received August 14,2012; Accepted November 13, 2012

DOI: $10.3892 / \mathrm{mmr} .2013 .1262$

\begin{abstract}
The purpose of this study was to investigate the expression of estradiol and estrogen receptor $\alpha(\operatorname{ESR} \alpha)$ in severe preeclamptic (sPE) pregnancies compared with normal pregnancies. Sera and placentas were obtained from i) patients with sPE $(n=25)$ and ii) a normal control group $(n=25)$ who underwent elective Cesarean deliveries. Estradiol expression was assessed by enzyme-linked immunosorbent assays (ELISAs). ESR $\alpha$ expression was assessed by reverse transcription polymerase chain reaction (RT-PCR) analysis and western blot analysis. In preeclamptic pregnancies, estradiol was underexpressed $(\mathrm{P}<0.05)$, however, ESR $\alpha$ mRNA and protein levels were increased significantly in comparison with normal pregnancies $(\mathrm{P}<0.05)$. These results show that estradiol and $\mathrm{ESR} \alpha$ are deregulated in preeclamptic pregnancies, which in turn suggests the involvement of these molecules in the pathogenesis of preeclampsia.
\end{abstract}

\section{Introduction}

Preeclampsia is a common pregnancy-specific syndrome that is characterized by hypertension and proteinuria. It is a disorder that affects at least $5 \%$ of all pregnancies worldwide (1) and

Correspondence to: Dr Xiaoming Zhu, Department of Obstetrics and Gynecology, Tangdu Hospital, Fourth Military Medical University, Xinsi Street, Xi'an, Shanxi 710038, P.R. China

E-mail: xiaomingzhu1981@hotmail.com

*Contributed equally

Key words: estradiol, estrogen receptor $\alpha$, preeclampsia, pregnancy is a leading cause of maternal and perinatal morbidity and mortality. Although the cause of preeclampsia remains unclear, it is generally agreed that preeclampsia results from the presence of a placenta (2) since the only treatment for preeclampsia is the delivery of the placenta, subsequent to which the symptoms regress rapidly. Previous studies in our laboratory have demonstrated that miR-18a was downregulated in preeclamptic placentas (3). miR-18a is a component of the miR-17-92 gene cluster which is located on chromosome 13q31.3. Evidence has shown that the ESR1 gene, which encodes estrogen receptor $\alpha$ $(\mathrm{ESR} \alpha)$, is a target of miR-18a (4).

Estrogen receptors (ESRs) are members of the nuclear receptor superfamily that mediate the pleiotropic effects of the steroid hormone estrogen in a diverse range of developmental and physiological processes (5). There are two forms of the ESR, ESR $\alpha$ and ESR $\beta$, each encoded by a separate gene (ESR1 and ESR2, respectively). ESR $\alpha$ is expressed mainly in the ovaries, uterus and placenta (6), while ESR $\beta$ is widely expressed in a number of tissues (7). The receptors are activated by the hormone $17 \beta$-estradiol $(6,7)$. Liu et al identified that miR-18a prevents translation of $\mathrm{ESR} \alpha$ by binding to its mRNA at the $3^{\prime}$ untranslated region, potentially blocking the protective effects of estrogen (4). These previous study findings suggest that miR-18a may be involved in the pathogenesis of preeclampsia through regulation of $\mathrm{ESR} \alpha$, which in turn suggests the involvement of ESR $\alpha$ and $17 \beta$-estradiol in the pathogenesis of preeclampsia.

A certain degree of attention has been given to $\operatorname{ESR} \alpha$, $17 \beta$-estradiol and preeclampsia. However, studies measuring $\operatorname{ESR} \alpha$ and $17 \beta$-estradiol from preeclamptic females have demonstrated inconsistent results, with certain studies revealing differential ESR $\alpha$ and estradiol expression in preeclampsia $(8,9)$ while others have shown no differences (10-12). For these reasons, we investigated the expression of estradiol and ESR $\alpha$ in severe preclamptic (sPE) pregnancies compared with normal 
Table I. Clinical characteristics of normal and preeclamptic pregnancies.

\begin{tabular}{lccc}
\hline Variable & Control $(\mathrm{n}=25)$ & sPE $(\mathrm{n}=25)$ & P-value ${ }^{\mathrm{a}}$ control vs. sPE \\
\hline Maternal age (years) & $30.8 \pm 2.1$ & $31 \pm 1.9$ & 0.912 \\
Gestational age (weeks) & $37.5 \pm 2.0$ & $36 \pm 2.7$ & 0.094 \\
Birth weight (g) & $3151 \pm 386$ & $3009 \pm 497$ & 0.314 \\
BMI $\left(\mathrm{kg} / \mathrm{m}^{2}\right)$ & $24.9 \pm 2.3$ & $24.1 \pm 2.4$ & 0.081 \\
Systolic blood pressure (mmHg) & $110.1 \pm 9.2$ & $169.6 \pm 26.2$ & $<0.01$ \\
Diastolic blood pressure (mmHg) & $69.1 \pm 8.2$ & $112.9 \pm 17.5$ & $<0.01$ \\
Proteinuria (g/24 h) & 0 & $2.9 \pm 1.5$ & $<0.01$ \\
\hline
\end{tabular}

All results are presented as mean \pm SD. sPE, severe preeclampsia. ${ }^{a}$ One-way ANOVA showed a statistically significant distribution of P-values

Table II. Primer sequences and reaction conditions for RT-PCR.

\begin{tabular}{llcr}
\hline Gene & \multicolumn{1}{c}{ Primer sequences } & Annealing temperature $\left({ }^{\circ} \mathrm{C}\right)$ & Cycle $(\mathrm{n})$ \\
\hline ESR $\alpha$ & 56 & 31 \\
$\beta$ F: CCTGGCTAGAGATCCTGAT & & 55 & 25 \\
& R: CCCTGGTTCCTGTCCAAGA & &
\end{tabular}

RT-PCR, reverse transcription polymerase chain reaction; F, forward; R, reverse.

pregnancies, with the hope that such associations may provide insights into the causal mechanisms of preeclampsia.

\section{Materials and methods}

Sample collection and hormone assay. Sera and placental tissues were obtained with informed consent from nulliparous females who were admitted to the Department of Obstetrics and Gynecology, Tangdu Hospital in Xi'an, China. The samples were obtained from patients with normal pregnancies (control group; $n=25$ ) and from patients with $\mathrm{sPE}(\mathrm{sPE}$ group; $n=25$ ). All females underwent an elective Cesarean delivery in the absence of labor; the clinical characteristics of the study groups are shown in Table I. Preeclampsia was defined according to the criteria of the International Society for the Study of Hypertension in Pregnancy $(13,14)$. sPE was defined as either severe hypertension (systolic blood pressure of $\geq 160 \mathrm{mmHg}$ and/or diastolic blood pressure of $\geq 110 \mathrm{mmHg}$ on at least 2 occasions $6 \mathrm{~h}$ apart) plus mild proteinuria ( $\geq 300 \mathrm{mg} / 24 \mathrm{~h}$ or $>1+$ by dipstick), or as mild hypertension (systolic blood pressure of $\geq 140 \mathrm{mmHg}$ and/or diastolic blood pressure of $\geq 90 \mathrm{mmHg}$ on at least 2 occasions $6 \mathrm{~h}$ apart) plus severe proteinuria $(>2 \mathrm{~g} / 24 \mathrm{~h}$ or $>2+$ by dipstick) $(13,14)$. No other maternal complications arose in any of the preeclamptic pregnancies, and none of our subjects had a birthweight of $<10 \%$ of average birthweight.

Tissue blocks $\left(\sim 1 \mathrm{~cm}^{3}\right.$ each) were sampled randomly from varying lobules (10 sites) of each placenta to achieve uniformity and adequate sampling. Villous portions were dissected from the decidual side of the placentas (avoiding macroscopic areas of necrosis and infarction), snap-frozen in liquid nitrogen overnight and stored at $-80^{\circ} \mathrm{C}$ until use. Blood was obtained from preeclamptic patients and normal control subjects and placed into a serum separation vacutainer tube before treatment. Serum was collected following centrifugation for $5 \mathrm{~min}$ at 3,000 rpm and was stored at $-80^{\circ} \mathrm{C}$ until the estimation of estradiol, which was performed by commercially available kits according to the manufacturer's instructions (Estradiol assay, Cobase601, Roche, Mannheim, Germany). The study protocol was approved by the review board of the Fourth Military Medical University (Xi'an, China).

Reverse transcription polymerase chain reaction (RT-PCR) analysis. RT-PCR analysis was performed on 50 tissue samples, one obtained from each subject. The total RNA was isolated from the placentas using TRIzol reagent (Invitrogen, Carlsbad, CA, USA) according to the manufacturer's instructions. The purity and concentration of the total RNA were measured on a spectrophotometer (Jenway Ltd., Bibby Scientific Limited, Staffordshire, UK) using their absorbance values (260/280 nm). RNA integrity was confirmed by electrophoresis in a $1.5 \%$ agarose denaturing gel and $1 \mu \mathrm{g}$ total RNA was subsequently reverse transcribed into cDNA using a RevertAid ${ }^{\mathrm{TM}}$ First Strand cDNA Synthesis kit (MBI, Fermentas, Vilnius, Lithuania).

The primers for the RT-PCR were designed according to specific cDNA sequences in the NCBI database (ESR $\alpha$, accession no: NM_000125; $\beta$-actin, accession no: NM_001101). The primer sequences and the reaction conditions are shown in Table II. A $25-\mu 1$ PCR master mix was prepared as follows: $1 \mu \mathrm{l}$ RT products, $200 \mu \mathrm{mol} / 1 \mathrm{dNTPs}, 2 \mathrm{mmol} / 1 \mathrm{MgCl}_{2}, 1 \mathrm{IU}$ Taq DNA polymerase and 10 pmol of each primer.

Amplification was ensured to occur within the exponential phase of PCR using preliminary experiments. PCR products 


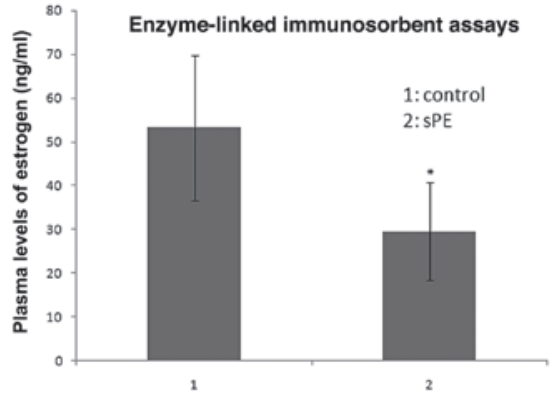

Figure 1. Comparison of estradiol expression between normal (control) and severe preeclamptic (sPE) serum samples. The concentrations of serum estradiol in preeclampsia were significantly lower than that in normal pregnant females $(29.550 \pm 11.172$ vs. $53.220 \pm 16.560 \mathrm{ng} / \mathrm{ml}$, respectively; independent t-test: $\mathrm{P}<0.05)$.

\section{A}

\section{RT-PCR}

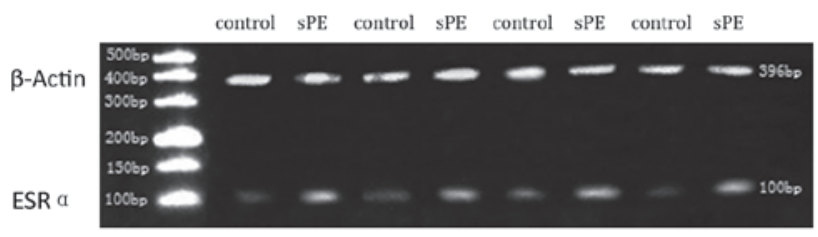

B

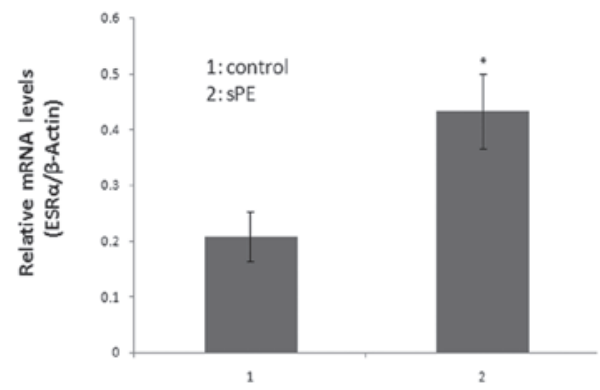

Figure 2. (A) Changes in the expression of ESR $\alpha$ mRNA in chorionic villi from normal (control) and severe preeclamptic (sPE) pregnancies. (B) Relative expression of ESR $\alpha$ was calculated by normalizing to $\beta$-actin expression. The mean level of ESR $\alpha$ mRNA in the preeclamptic chorionic villi was significantly higher than that in normal controls: $0.432 \pm 0.067$ (sPE) and $0.207 \pm 0.044$ (control) by densitometric quantitation (independent t-test: $\mathrm{P}<0.05)$. ESR $\alpha$, estrogen receptor $\alpha$.

were subjected to electrophoresis on agarose gels and the relative densities of ESR $\alpha$ genes normalized to $\beta$-actin were analyzed using the Image-Pro plus (software version 6.0; Media Cybernetics, Silver Spring, MD, USA).

Western blot analysis. Tissues were homogenized and incubated on ice in PRO-PREP ${ }^{\mathrm{TM}}$ Protein Extraction Solution (SBS, Beijing, China). The supernatant was collected and protein estimation was carried out using the Bradford method. A total of $50 \mu \mathrm{g}$ of protein per lane was used for western blot analysis. All proteins were heated at $100^{\circ} \mathrm{C}$ and separated by sodium dodecyl sulfate-polyacrylamide gel electrophoresis (SDS-PAGE) on a 10\% gel. The proteins were next transferred to a polyvinylidene difluoride membrane (Hybond, Amersham Biosciences, Little Chalfont, UK) by semi-dry electroblotting. Nonspecific reactivity was blocked by placing the membrane in 5\% skimmed milk in PBST. The membrane was then incu-
A Western blot analysis

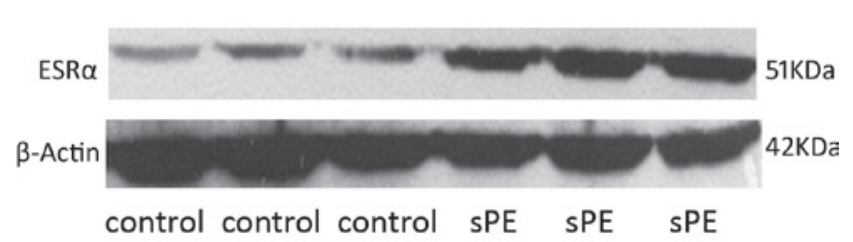

B

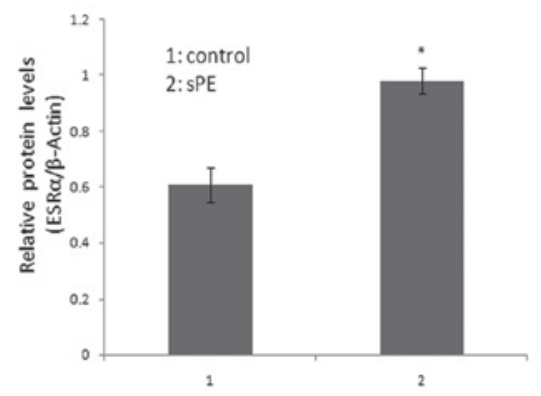

Figure 3. (A) Comparison of ESR $\alpha$ protein between the normal (control) and severe preeclamptic (sPE) chorionic villi. (B) The mean level of ESR $\alpha$ protein corrected by $\beta$-actin protein in the preeclamptic villi was significantly higher than that in normal controls: $0.98 \pm 0.047$ (sPE) and $0.61 \pm 0.061$ (control) by densitometric quantitation (independent t-test: $\mathrm{P}<0.05$ ). $\mathrm{ESR} \alpha$, estrogen receptor $\alpha$.

bated with rabbit antibodies against human $\operatorname{ESR} \alpha(1: 2,500$, Epitomic, Burlingame, CA, USA). The membrane was subsequently washed in PBST and incubated with horseradish peroxidase secondary antibody (1:5,000, Kangwei, Beijing, China). Chemiluminescent detection was carried out using the Enhanced Chemiluminescent Substrate (Pierce, Rockford, IL, USA). Subsequent to stripping, the same membrane was used to reprobe with the rabbit-anti-human $\beta$-actin antibody $(1: 3,000$, Abcam, Cambridge, UK) to detect $\beta$-actin as the internal loading control.

Statistical analysis. All values are presented as the mean \pm SD of three individual experiments performed in triplicate. Comparison of the values between groups was performed using one-way ANOVA by SPSS 11.0 software. P $<0.05$ was considered to indicate a statistically significant difference.

\section{Results}

Estradiol expression in normal and preeclamptic serum samples. Estradiol serum concentrations that were measured in the 25 normal pregnant females ranged between 23.06 and $85.90 \mathrm{ng} / \mathrm{ml}$, with a median value of $53.220 \mathrm{ng} / \mathrm{ml}$. By contrast, estradiol serum concentrations that were measured in the 25 patients with preeclampsia ranged between 9.54 and $59.15 \mathrm{ng} / \mathrm{ml}$, with a median value of $29.550 \mathrm{ng} / \mathrm{ml}$. The estradiol serum concentrations were significantly lower in the preeclamptic pregnant females than in the normal pregnant females $(29.550 \pm 11.172$ vs. $53.220 \pm 16.560 \mathrm{ng} / \mathrm{ml}$, respectively; $\mathrm{P}<0.05$; Fig. 1).

ESR $\alpha$ expression in normal and preeclamptic chorionic villi. We compared the expression levels of ESR $\alpha$ mRNA in chorionic villi from normal pregnancies with those from patients 
with sPE using RT-PCR analysis. Relative expression of ESR $\alpha$ was calculated by normalizing to $\beta$-actin expression. The mean level of ESR $\alpha$ mRNA in the preeclamptic chorionic villi was significantly higher than that of normal controls $(\mathrm{P}<0.05)$ : $0.432 \pm 0.067$ (sPE) and $0.207 \pm 0.044$ (control) by densitometric quantitation (Fig. 2).

To determine whether the mRNA levels correlated with the amount of ESR $\alpha$ protein, we measured the ESR $\alpha$ protein expression by western blot analysis. Similar results were obtained as shown in Fig. 3; the mean level of ESR $\alpha$ protein corrected by $\beta$-actin protein was significantly higher in the preeclamptic villi than that in normal controls $(\mathrm{P}<0.05)$ : $0.98 \pm 0.047$ (sPE) and $0.61 \pm 0.061$ (control) by densitometric quantitation.

\section{Discussion}

The present study demonstrated a significant decrease in the expression of estradiol in patients with $\mathrm{sPE}$, and a significant increase of ESR $\alpha$ expression in preeclamptic pregnancies compared with normal pregnancies.

The estrogens are a group of sex hormones secreted primarily by the ovaries, however, during pregnancy estrogen is secreted by the placenta. Estrogen is involved in the development and maintenance of the female phenotype, germ cell maturation and pregnancy. There are several types of estrogen but the three main types are estrone (E1), estradiol (E2) and estriol (E3). At equal concentrations, E2 has a stronger biological effect than E1 which in turn is more powerful than E3 (15). We therefore investigated the E2 level (but not E1 or E3) by enzyme-linked immunosorbent assay (ELISA) analysis, and detected that E2 was underexpressed in preeclamptic pregnancies when compared with normal pregnancies. These results are similar to the findings recorded by Zeisler $e t$ al and Hertig et al $(9,16)$. Normal pregnancy itself is a state of systemic inflammation with an elevation in the white blood cell count. However, the immune system is suppressed during normal pregnancy in order to protect the fetus against immune cell lysis. It is generally agreed that there is an activated systemic maternal inflammatory response in preeclampsia (17) that affects the circulating leukocytes, and that circulating IL-6 and IL-8 are increased in preeclampsia. Evidence indicates that estradiol has an anti-inflammatory effect (18). Schaefer et al observed that estradiol has an inhibitory effect on IL-1 $\beta$-mediated inflammatory responses in uterine epithelial cells, which suggests a link between the endocrine and immune systems, and indicates that estradiol may be crucial for protecting the fetus against immune cells lysis during pregnancy (19). Therefore, the significant decrease in the expression of estradiol in patients with sPE may impair this ability to protect the fetus against immune cells lysis.

Estrogens mediate their action on a target tissue by binding to their receptors, which are nuclear transcription factors. To date, two ESRs (ESR $\alpha$ and ESR $\beta$ ), encoded by different genes, have been described (20). ESR $\alpha$ is expressed predominantly in the ovaries, uterus, testes and placenta, while ESR $\beta$ is expressed in numerous systems and tissues, including the central nervous, cardiovascular and immune systems and the urogenital and gastrointestinal tracts (21). In the uterus, there is a greater quantity of ESR $\alpha$ present than ESR $\beta$. Also, it is now evident that ESR $\alpha$ is mainly involved in reproductive events (22). We therefore investigated the ESR $\alpha$ level (but not ESR $\beta$ ) by RT-PCR and western blot analysis, and identified that ESR $\alpha$ mRNA and protein levels were increased significantly in comparison with normal pregnancies $(\mathrm{P}<0.05)$. ESR $\alpha$ is known to play a significant role in proliferation in the maturation of estrogen-dependent cells (23). Eissa et al stated that significantly enhanced ESR expression is exhibited in term deciduas from females with SPE, which indicates a unique role for ESR in pregnancy (8). Since the trophoblast is a major source of placental hormones, ESR $\alpha$ expression by trophoblast cells may be involved in the stimulation of placental hormonal estrogen production. We observed a significant decrease in the expression of estradiol in patients with sPE, whereas the increased ESR $\alpha$ expression may be a compensatory mechanism in these cases.

It should be noted that there are two existing forms of preeclampsia: early-onset (symptoms at $<34$ weeks, type I) and late-onset (symptoms at $>34$ weeks, type II). Early-onset preeclampsia is associated with placental risk factors, while late-onset preeclampsia is associated with the female etiology connected with disturbances in factors regulating inflammatory process, implantation and placentation (24). As placental tissues of $<34$ weeks of gestation were not easily obtainable, we used placental tissues of $36 \pm 2.7$ weeks gestation (Table I) in the present study. Further investigation is required to clarify the differences in estradiol and ESR $\alpha$ expression between early-onset and late-onset preeclampsia.

Further studies have been carried out by our study group in order to unravel the mechanisms of upregulating ESR $\alpha$ expression in preeclamptic placentas. We have been focused on miRNAs, noncoding RNA molecules of 21 to $24 \mathrm{nt}$ that regulate the expression of target genes in a post-transcriptional manner (25). We have carried out a comparison between the miRNA expression profiles of the PE placentas and the controls. Through microarray analysis and real time RT-PCR confirmation, we have identified certain miRNAs that are differently expressed in PE placentas, and from using computational target predictions we have also identified that the targets of these miRNAs included ESR $\alpha$ (3), suggesting that miRNAs were potentially involved in the regulation of ESR $\alpha$ expression. Further studies using miRNAs and ESR $\alpha$ are currently ongoing in our group.

In summary, estradiol expression was demonstrated to be significantly lowered in preeclamptic pregnancies, while we observed a significant increase in the expression of ESR $\alpha$ for patients with SPE. Our findings suggest that estradiol and ESR $\alpha$ may be involved in placentation and may be factors in the etiology of PE.

\section{Acknowledgements}

This study was supported in part by the Chinese Natural Science Foundation, Grants No. 31000660 (X.-M.Z.) and No. 30973208 (G.-W.Y.) and the Tangdu Hospital Elite Talent Fund (X.-M.Z.).

\section{References}

1. Driul L, Damante G, D'Elia A, Springolo F, Ianni A, Di Leonardo C, Angelini M and Marchesoni D: Screening for pre-eclampsia in a low-risk population at 24 weeks: uterine artery Doppler flow velocimetry and genetic variants of factor $\mathrm{V}$, prothrombin and methylenetetrahydrofolate reductase. Minerva Ginecol 56: 385-390, 2004 (In Italian). 
2. Redman CW: Current topic: pre-eclampsia and the placenta Placenta 12: 301-308, 1991.

3. Zhu XM, Han T, Sargent IL, Yin GW and Yao YQ: Differential expression profile of microRNAs in human placentas from preeclamptic pregnancies vs normal pregnancies. Am J Obstet Gynecol 200: 661.e1-e7, 2009.

4. Liu WH, Yeh SH, Lu CC, Yu SL, Chen HY, Lin CY, Chen DS and Chen PJ: MicroRNA-18a prevents estrogen receptor-alpha expression, promoting proliferation of hepatocellular carcinoma cells. Gastroenterology 136: 683-693, 2009.

5. Shao W and Brown M: Advances in estrogen receptor biology: prospects for improvements in targeted breast cancer therapy. Breast Cancer Res 6: 39-52, 2004.

6. Kuiper GG, Carlsson B, Grandien K, Enmark E, Häggblad J Nilsson S and Gustafsson JA: Comparison of the ligand binding specificity and transcript tissue distribution of estrogen receptors alpha and beta. Endocrinology 138: 863-870, 1997.

7. Kuiper GG, Enmark E, Pelto-Huikko M, Nilsson S and Gustafsson JA: Cloning of a novel receptor expressed in rat prostate and ovary. Proc Natl Acad Sci USA 93: 5925-5930, 1996

8. Eissa S, Mostafa MM, El-Gendy AA and Senna IA: Quantitative immunological detection of total estrogen receptor (cytosolic and nuclear) in term decidua of preeclampsia: a preliminary study. Clin Chem 43: 405-406, 1997.

9. Zeisler H, Jirecek S, Hohlagschwandtner M,Knöfler M, Tempfer C and Livingston JC: Concentrations of estrogens in patients with preeclampsia. Wien Klin Wochenschr 114: 458-461, 2002.

10. Schiessl B, Mylonas I, Hantschmann P, Kuhn C, Schulze S, Kunze S, Friese K and Jeschke U: Expression of endothelial NO synthase, inducible NO synthase, and estrogen receptors alpha and beta in placental tissue of normal, preeclamptic, and intrauterine growth-restricted pregnancies. J Histochem Cytochem 53: 1441-1449, 2005.

11. Troisi R, Potischman N, Roberts JM, Ness R, Crombleholme W, Lykins D, Siiteri P and Hoover RN: Maternal serum oestrogen and androgen concentrations in preeclamptic and uncomplicated pregnancies. Int J Epidemiol 32: 455-460, 2003.

12. Acromite M, Ziotopoulou M, Orlova C and Mantzoros C: Increased leptin levels in preeclampsia: associations with BMI, estrogen and SHBG levels. Hormones (Athens) 3: 46-52, 2004

13. ACOG Committee on Practice Bulletins - Obstetrics: ACOG practice bulletin. Diagnosis and management of preeclampsia and eclampsia. Number 33, January 2002. Obstet Gynecol 99: $159-167,2002$

14. National Institutes of Health; National Heart, Lung and Blood Institute; National High Blood Pressre Program: Working Group Report on High Blood Pressure in Pregnancy. NIH Publication No. 00-3029, revised 2000
15. Romani W, Patrie J, Curl LA and Flaws JA: The correlations between estradiol, estrone, estriol, progesterone, and sex hormone-binding globulin and anterior cruciate ligament stiffness in healthy, active females. J Womens Health (Larchmt) 12: 287-298, 2003 .

16. Hertig A, Liere P, Chabbert-Buffet N, Fort J, Pianos A, Eychenne B, Cambourg A, Schumacher M, Berkane N, Lefevre G, et al: Steroid profiling in preeclamptic women: evidence for aromatase deficiency. Am J Obstet Gynecol 203 : 477.e1-e9, 2010.

17. Redman CW and Sargent IL: Pre-eclampsia, the placenta and the maternal systemic inflammatory response - a review. Placenta 24 (Suppl A): S21-S27, 2003

18. Molloy EJ, O'Neill AJ, Grantham JJ, Sheridan-Pereira M, Fitzpatrick JM, Webb DW and Watson RW: Sex-specific alterations in neutrophil apoptosis: the role of estradiol and progesterone. Blood 102: 2653-2659, 2003.

19. Schaefer TM, Wright JA, Pioli PA and Wira CR: IL-1betamediated proinflammatory responses are inhibited by estradiol via down-regulation of IL-1 receptor type I in uterine epithelial cells. J Immunol 175: 6509-6516, 2005

20. Sowers MR, Jannausch ML, McConnell DS, Kardia SR and Randolph JF Jr: Endogenous estradiol and its association with estrogen receptor gene polymorphisms. Am J Med 119 (9 Suppl 1): S16-S22, 2006

21. Drummond AE, Baillie AJ and Findlay JK: Ovarian estrogen receptor alpha and beta mRNA expression: impact of development and estrogen. Mol Cell Endocrinol 149: 153-161, 1999.

22. Gustafsson JA: Estrogen receptor beta - a new dimension in estrogen mechanism of action. J Endocrinol 163: 379-383, 1999.

23. Bukovsky A, Caudle MR, Cekanova M, Fernando RI, Wimalasena J, Foster JS, Henley DC and Elder RF: Placental expression of estrogen receptor beta and its hormone binding variant - comparison with estrogen receptor alpha and a role for estrogen receptors in asymmetric division and differentiation of estrogen-dependent cells. Reprod Biol Endocrinol 1: 36 , 2003.

24. Cudihy D and Lee RV: The pathophysiology of pre-eclampsia: current clinical concepts. J Obstet Gynaecol 29: 576-582, 2009.

25. Pasquinelli AE, Hunter S and Bracht J: MicroRNAs: a developing story. Curr Opin Genet Dev 15: 200-205, 2005. 